\title{
Pendekatan Pencegahan Kaunselor Muslim dalam Menangani Salah Laku Pelajar Sekolah Menengah di Daerah Klang, Selangor
}

\author{
The Preventive Approaches of Muslim Counselor in Dealing with Secondary School Students \\ Misbehavior in Klang District, Selangor
}

HALIMAH ABD HALIM* \& ZAINAB ISMAIL ${ }^{1}$

\begin{abstract}
Muslim counselor in school is a professional guide who can help schools to reduce students' misbehavior and to implement Islamic values as a way of life. The Islamic approach is the approach implemented by the school counselor in dealing student's misbehavior. However, the practice of Islamic approach using by Muslim counselor at school in dealing with students' misbehavior has not been studied extensively. This paper is aimed to discuss and analyze the Islamic approach adopted by the Muslim counselor as an effort to deal the students' misbehavior in secondary schools in Klang District, Selangor. Data in this paper were collected through a quantitative survey research. By using purposive sampling, a total of 73 Muslim counselors from secondary schools in the Klang District were selected as respondents. Data were analyzed using descriptive statistical techniques. The study shows that Muslim counselor in schools has implemented the Islamic preventive approach through programs such as anti-smoking talks, HIV and AIDS talks, selfidentity courses, leadership courses, religious talks, and visiting program to rehabilitation center. This study also shows that Muslim counselor practicing Islamic preventive approach in dealing students' misbehavior such as guiding students to perform solat fardu five times a day, to respect human being and environment, to behave with persistence, to commit with a good or ma'ruf deed, and to select a good mass media. As a whole, the Islamic preventive approach by the Muslim counselor has given a huge implication especially to develop an Islamic counseling index in dealing students' misbehavior.
\end{abstract}

Keywords: Muslim counselor, school counselling, student misbehavior

Kaunselor Muslim di sekolah adalah pembimbing profesional yang dapat membantu mengurangkan salah laku pelajar, di samping mampu untuk menerapkan nilai keislaman dalam diri pelajar. Bagi mencapai tujuan mengurangi salah laku pelajar, kaunselor Muslim sewajarnya mengamalkan pendekatan Islam yang merupakan teras kepada penyelesaian masalah terutamanya dalam menangani salah laku pelajar yang beragama Islam (Mohamed Sharif et al. 2003). Amalan pendekatan Islam oleh kaunselor Muslim di sekolah dilihat menjadi satu keperluan memandangkan senario salah laku disiplin pelajar yang semakin membimbangkan.

\footnotetext{
1 Halimah Abd Halim*(Corresponding author), Masters candidate at Department of Dakwah and Leadership Studies, Faculty of Islamic Studies, Universiti Kebangsaan Malaysia, 43600 BANGI, Selangor, Malaysia. email: mrshalimah016@gmail.com; Zainab Ismail, PhD., Professor at Department of Dakwah and Leadership Studies, Faculty of Islamic Studies, Universiti Kebangsaan Malaysia, 43600 BANGI, Selangor, Malaysia. email: zainab@ukm.edu.my.
} 
Mengikut kepada statistik dan laporan peratusan salah laku disiplin murid sekolah menengah bagi tahun 2013 di daerah Klang sahaja menunjukkan bahawa terdapat sebanyak 6496 kesalahan yang dilakukan oleh pelajar, seramai 3396 orang pelajar yang melakukan kesalahan manakala seramai 2599 orang pelajar perlu diberi sesi kaunseling. Ini bererti, sebanyak $27.5 \%$ pelajar di daerah Klang daripada sejumlah 9492 orang pelajar yang memerlukan sesi kaunseling bagi seluruh daerah di negeri Selangor (Jabatan Pendidikan Selangor 2014).

Kajian oleh Mardzelah (2012), Ishak (2012), Siti Hairaney (2004), mendapati di antara punca berlakunya salah laku dalam kalangan pelajar disebabkan oleh faktor agama iaitu kurangnya amalan kerohanian dan penghayatan agama dalam diri mereka. Kajian oleh Abu Mansor Mat Urdi (2005) turut mendapati bahawa pelajar yang kerap melaksanakan amalan agama dalam kehidupan mereka tidak akan melakukan sebarang salah laku di sekolah. Ini selaras dengan pandangan Othman Najati (1992) bahawa krisis yang dihadapi oleh manusia pada masa kini wujud kerana peminggiran mereka kepada agama serta nilai-nilai kerohanian. Malahan, Hassan Langgulung (1983) di dalam kajiannya juga mendapati bahawa remaja lelaki dan perempuan masing-masing memerlukan kepada agama seperti ingin mendalami ilmu alQuran, ingin mendekatkan diri kepada Allah (s.w.t.) serta mempunyai perasaan takut diseksa pada hari akhirat. Ini menunjukkan pelajar memerlukan kepada agama sebagai panduan hidup. Zulkefli (2007) di dalam kajiannya mencadangkan bahawa pendekatan berasaskan kerohanian paling wajar dilaksanakan kerana kebanyakan pelajar pada masa kini mengalami kekurangan terhadap aspek kerohanian.

Namun, kajian mengenai amalan pendekatan Islam oleh kaunselor Muslim dalam menangani salah laku pelajar masih belum dikaji secara menyeluruh. Tambahan pula, menurut Khadijah Rohani dan Nazariah (2007), pendekatan pencegahan merupakan pendekatan yang sesuai dilaksanakan di peringkat persekolahan bertujuan untuk mendidik pelajar mengenal pasti kebaikan dan keburukan sekiranya mereka terlibat dalam sesuatu tingkah laku. Pernyataan ini selari dengan pendapat Maznah dan Zainal (2007) yang berpandangan bahawa institusi pendidikan lebih memfokuskan kepada aspek pencegahan dan perkembangan potensi berbanding institusi pemulihan yang meletakkan pemulihan sebagai tujuan utama perkhidmatan. Oleh yang demikian, pengkaji cenderung untuk mengenal pasti terlebih dahulu pendekatan pencegahan oleh kaunselor Muslim dalam menangani salah laku pelajar sekolah menengah di daerah Klang termasuklah menganalisis amalan pendekatan Islam yang ada diamalkan oleh kaunselor Muslim di sekolah.

Persoalannya apakah pendekatan pencegahan yang dilaksanakan oleh kaunselor Muslim dalam menangani salah laku pelajar sekolah menengah di daerah Klang? Bagaimanakah amalan pendekatan Islam oleh kaunselor Muslim dalam menangani salah laku pelajar? Maka persoalan tersebut perlu dijawab dengan mengemukakan satu kajian Pendekatan Pencegahan Kaunselor Muslim dalam Menangani Salah Laku Pelajar Sekolah Menengah di Daerah Klang, Selangor perlu dilakukan. Justeru, objektif kajian ini adalah untuk mengenal pasti pendekatan pencegahan oleh kaunselor Muslim dalam menangani salah laku pelajar sekolah menengah di Daerah Klang, Selangor dan menganalisis amalan pendekatan Islam oleh kaunselor Muslim dalam menangani salah laku pelajar sekolah menengah di Daerah Klang, Selangor.

\section{Tinjauan Literatur}

Berdasarkan tinjauan terhadap kajian-kajian lepas, pada umumnya terdapat banyak penulisan oleh para sarjana kaunseling yang membincangkan mengenai kaunselor sekolah secara konsep meliputi peranan seorang kaunselor sekolah termasuklah mengaitkan peranan secara afektif oleh kaunselor dengan memahami objektif perkhidmatan bimbingan dan kaunseling seperti yang digariskan di dalam buku Panduan Pelaksanaan Perkhidmatan Bimbingan dan Kaunseling 
di Sekolah Menengah (1993). Pendekatan-pendekatan kaunseling yang terdapat di dalam objektif perkhidmatan bimbingan dan kaunseling di sekolah iaitu pendekatan perkembangan, pendekatan pencegahan, pendekatan pemulihan dan pendekatan krisis. Pendekatan perkembangan iaitu satu usaha untuk mengenal pasti keperluan pelajar di alam persekolahan agar mereka dilengkapi dengan pengetahuan, kemahiran, pengalaman serta akhlak yang mulia. Pendekatan pencegahan iaitu usaha yang dijalankan untuk menghalang satu-satu masalah yang mungkin timbul dan akan meruncing. Pendekatan pemulihan pula bererti pendekatan yang memberi fokus kepada kekurangan atau masalah yang dapat dikenal pasti dari semasa ke semasa, langkah mengatasi dijalankan dengan harapan pelajar mengubah kelakuannya untuk mengelakkan berlaku peristiwa krisis. Manakala pendekatan krisis bermaksud pendekatan yang mengendalikan kes krisis yang timbul secara mendadak dan memerlukan perhatian dan tindakan segera dari guru bimbingan dan kaunseling (Kementerian Pendidikan Malaysia 1993).

Namun, Maznah dan Zainal (2007) berpandangan bahawa institusi pendidikan lebih memfokuskan kepada aspek pencegahan dan perkembangan potensi berbanding institusi pemulihan yang meletakkan pemulihan sebagai tujuan utama perkhidmatan. Program pencegahan yang dilaksanakan di sekolah iaitu kempen dan pameran pencegahan rokok, AIDS dan HIV, kursus kepimpinan diri, kursus jati diri dan kursus bina insan. Manakala program perkembangan potensi diri iaitu taklimat persediaan menghadapi peperiksaan, taklimat IPT, ceramah motivasi, ceramah awal remaja, ceramah kerjaya, program orientasi dan maju diri (Kementerian Pendidikan Malaysia 1993). Program pencegahan yang dinyatakan ini dilihat selari dengan penulisan artikel oleh Sapora (2002), yang menjelaskan aspek pencegahan meliputi usaha-usaha yang boleh dijalankan oleh kaunselor sekolah seperti menanam nilai-nilai positif yang bersesuaian dengan norma masyarakat melalui penganjuran aktiviti-aktiviti bimbingan dan kaunseling yang terancang.

Tinjauan kajian lepas mengenai seputar kaunselor Muslim turut disoroti. Terdapat banyak penulisan oleh tokoh-tokoh kaunseling Islam yang membincangkan mengenai konsep kaunselor Muslim seperti Ishammudin (2000), Aziz (1996), Kamal (1995) dan Abdul Kadir (1990) meliputi etika dan ciri kaunselor Muslim, peranan kaunselor Muslim serta pendekatan Islam di dalam kaunseling. Pendekatan Islam yang dibincangkan iaitu mendekati klien dengan penuh hikmah, nasihat yang baik dan perbincangan yang baik sepertimana yang dianjurkan oleh al-Quran surah al-Nahl ayat 125. Aziz (1996) dilihat mempunyai perspektif khusus berkenaan dengan tujuan kaunseling iaitu membantu dan memberi kefahaman kepada klien dalam menghadapi cabaran persekitaran, membimbing klien yang terlibat dalam perbuatan keji seperti maksiat, penyalahgunaan dadah, disiplin di sekolah dan segala perkara yang dilarang oleh Allah (s.w.t.) selain membantu membentuk tabiat diri klien agar sentiasa berdisiplin. Perspektif Aziz (1996) berkenaan dengan tujuan kaunseling ini bersesuaian dengan persekitaran hidup yang semakin mencabar dan perlu kepada kaunseling. Jika dikaji kebanyakan penulisan oleh tokoh-tokoh kaunseling ini memberi penekanan kepada ayat 2 surah al-Ma'idah yang menjelaskan tentang galakan Allah (s.w.t.) kepada setiap Muslim untuk bantu-membantu ke arah kebajikan dan ketakwaan. Ayat ini dilihat menjadi pengukur dalam memperihalkan berkenaan peranan kaunselor Muslim. Malah, menurut ahli tafsir iaitu alMaraghi (1998M, Jil. 1), elemen bantu membantu dalam melaksanakan kebajikan dan ketakwaan merupakan satu aspek penting untuk membimbing masyarakat berpandukan alQuran dan al-Sunnah.

Menurut Othman Najati (1992), ketakwaan menjadi faktor utama yang memandu kepada perkembangan diri dengan melahirkan tingkah laku yang lebih baik serta menghindarkan diri daripada tingkah laku yang buruk. Manakala pemulihan dan pencegahan jiwa manusia berasaskan kepada Rukun Islam yang lima iaitu solat fardu lima waktu, berpuasa pada bulan Ramadan, berzakat dan menunaikan haji. Kesemua ini merupakan kaedah 
pencegahan dan terapeutik yang mampu untuk mendidik keperibadian manusia. Di samping itu, Amaludin (2005) di dalam tesisnya mengemukakan satu model perkhidmatan kaunseling Islam yang boleh dilaksanakan oleh kaunselor Muslim. Di dalam model ini, penulis menyenaraikan aspek-aspek pendekatan pencegahan yang dapat membimbing klien kepada Islam seperti menyuruh kepada kebaikan (makruf), mencegah daripada kejahatan (munkar), memberi maklumat berkaitan akhlak dan salah laku, serta membimbing klien agar dapat membezakan di antara perbuatan yang mendapat dosa, pahala, perkara yang halal dan haram.

Selain itu, terdapat penulisan yang membincangkan mengenai peranan guru dalam menangani salah laku disiplin melalui pendekatan modal insan. Penulisan oleh Ishak dan Khairun Nisa (2010) ini membincangkan peranan yang sewajarnya dimainkan oleh guru dalam menangani masalah disiplin pelajar berdasarkan kepada strategi pembentukan modal insan yang terkandung dalam Teras Kedua Pelan Induk Pembangunan Pendidikan (2006-2010). Pelan ini memberi tumpuan terhadap pembentukan keterampilan dan keperibadian pelajar yang salah satunya melalui pengukuhan disiplin pelajar. Penulisan ini memberi penekanan bahawa setiap guru adalah pendidik. Menurut penulis, guru yang berhadapan dengan pelajar yang bermasalah tingkah laku perlu berperanan menasihati pelajar itu supaya menghindari perbuatan tersebut dan membimbing cara pertuturan dan tingkah laku yang betul. Justeru, dalam penulisan ini turut dijelaskan kaedah mencegah pelajar daripada bermasalah salah laku melalui pendekatan bimbingan dan penasihatan.

Di samping itu, terdapat kajian-kajian lepas yang mengkaji seputar pendekatan yang di ambil oleh individu atau sesebuah organisasi dalam menangani salah laku disiplin pelajar. Kajian oleh Zulkefli (2007) yang bertajuk Pendekatan Pentadbir Sekolah dalam Menangani Salah Laku Murid Sekolah Menengah di Kuala Lumpur, mengkaji tentang pendekatan oleh pentadbir sekolah yang terdiri daripada pengetua, penolong kanan, guru disiplin dan kaunselor sekolah dalam menangani salah laku pelajar. Kajian menggunakan reka bentuk kajian kes berganda ini membincangkan enam pendekatan dalam menangani salah laku pelajar iaitu pendekatan hukuman, pendekatan kaunseling, pendekatan kokurikulum, pendekatan program pencegahan salah laku, pendekatan kerjasama polis, badan bukan kerajaan (NGO) dan masyarakat serta pendekatan aspek sosial dalam 'Dasar Sekolah Selamat'. Pun begitu, dapatan kajian juga menemui dua pendekatan lain hasil daripada temu bual dengan pentadbir sekolah iaitu pendekatan kerohanian dan pendekatan kemanusiaan. Pendekatan kerohanian yang diertikan oleh pengkaji ini iaitu nasihat berunsur keagamaan manakala pendekatan kemanusiaan diertikan sebagai perhatian dan kasih sayang. Hasil kajian menunjukkan bahawa kedua-dua pendekatan ini diakui keberkesanannya oleh pentadbir sekolah dalam menangani salah laku pelajar.

Selain itu, penulisan artikel oleh Khalim dan Wan Zulkifli (2009) bertajuk Pendekatan Islam dalam Menangani Masalah Disiplin Tegar dalam Kalangan Pelajar Sekolah: Satu Kajian Kes bertujuan untuk menilai keberkesanan pendekatan Islam terhadap pelajar yang bermasalah disiplin tegar. Seramai sepuluh orang pelajar disiplin tegar dipilih dalam kajian serta diberikan program pemulihan iaitu membaca al-Quran, menunaikan solat Duha dan tazkirah. Program ini berjalan daripada bulan Januari hingga November sepanjang sesi persekolahan. Hasil kajian mendapati seramai lapan daripada sepuluh orang pelajar telah berubah tingkah laku mereka dan menjadi pelajar yang berdisiplin. Walaupun kajian ini menjurus kepada perbincangan terhadap program pemulihan pendekatan Islam dan keberkesanannya terhadap pelajar bermasalah disiplin tegar, namun dilihat wujud aspek pencegahan iaitu menunaikan solat dan tazkirah yang tentunya terdapat unsur-unsur nasihat dan bimbingan ke arah keimanan dan ketakwaan yang mampu mencegah pelajar daripada melakukan tingkah laku yang tidak baik. Justeru, dapat disimpulkan bahawa terdapat kajian-kajian lepas yang mengkaji seputar pendekatan pencegahan yang diambil dalam usaha menangani salah laku pelajar. Namun kajian 
mengenai pendekatan pencegahan oleh kaunselor Muslim dalam menangani salah laku pelajar sekolah menengah didapati masih belum dikaji secara menyeluruh.

\section{Metodologi Kajian}

Kajian ini merupakan kajian kuantitatif dengan reka bentuk kajian tinjauan. Borang soal selidik telah digunakan sebagai alat pengumpulan data. Responden dalam kajian ini terdiri daripada 73 orang kaunselor Muslim sekolah menengah di daerah Klang, Selangor. Kaunselor Muslim ini mendapat pendidikan ikhtisas dalam bidang bimbingan dan kaunseling sama ada di peringkat diploma, ijazah sarjanamuda atau ijazah sarjana yang melayakkan mereka menjadi guru kaunselor sepenuh masa di sekolah. Pemilihan responden dilakukan secara bertujuan. Pemilihan kawasan kajian adalah di sekolah-sekolah menengah daerah Klang, Selangor kerana statistik salah laku pelajar tahun 2013 menunjukkan seramai 27.5\% pelajar yang terlibat dengan salah laku memerlukan sesi kaunseling. Ini menunjukkan daerah Klang mencatat statistik kedua tertinggi peratusan pelajar yang memerlukan sesi kaunseling daripada 10 daerah di bawah Pejabat Pendidikan Daerah di Negeri Selangor. Kajian rintis telah dijalankan untuk melihat kebolehpercayaan instrumen kajian. Data perolehan dianalisis menggunakan ujian analisis kebolehpercayaan untuk mendapatkan nilai Alpha Cronbach. Nilai Alpha Cronbach bagi instrumen kajian ini adalah sangat memuaskan iaitu 0.916 bagi konstruk pendekatan pencegahan dan 0.868 bagi konstruk pendekatan program khas. Data-data daripada borang soal selidik dianalisis menggunakan statistik deskriptif dan dipersembahkan dalam bentuk kekerapan, peratusan dan min.

\section{Hasil Kajian dan Perbincangan}

Hasil kajian mendapati bahawa kaunselor Muslim sekolah menengah di daerah Klang, Selangor melaksanakan pendekatan pencegahan sebagai usaha mereka dalam menangani salah laku pelajar di sekolah. Pendekatan pencegahan yang dikenal pasti dalam kajian ini iaitu berbentuk program-program khas. Justeru, kajian mendapati item 'Saya mengadakan program pencegahan berbentuk ceramah anti rokok, HIV dan AIDS dalam menangani salah laku pelajar' mencapai nilai min paling tinggi $(\mathrm{min}=4.36$ ) diikuti dengan item 'Saya mengadakan program pencegahan berbentuk pameran anti rokok, HIV dan AIDS dalam menangani salah laku pelajar' (min=4.32). Selain itu, item 'Saya mengadakan program pencegahan berbentuk kursus jati diri dalam menangani salah laku pelajar' $(\mathrm{min}=4.30)$ manakala item 'Saya mengadakan program pencegahan berbentuk kursus kepimpinan diri dalam menangani salah laku pelajar' $(\min =4.26)$. Seterusnya item 'Saya mengadakan program pencegahan berbentuk ceramah agama dalam menangani salah laku pelajar' $(\min =4.18)$. Walau bagaimanapun, item yang mendapat nilai min terendah iaitu 'Saya mengadakan program pencegahan berbentuk lawatan ke pusat pemulihan akhlak dalam menangani salah laku pelajar' (min=3.58). Ini menunjukkan responden bersetuju dengan empat jenis program pendekatan pencegahan yang dianjurkan iaitu ceramah, lawatan, pameran dan kursus.

Dapatan menunjukkan bahawa responden sentiasa komited dalam melaksanakan program-program khas berbentuk pencegahan seperti yang ditetapkan di dalam buku Panduan Pelaksanaan Perkhidmatan Bimbingan dan Kaunseling di Sekolah Menengah (1993). Ini berdasarkan kepada tahap persetujuan yang tinggi oleh responden terhadap program-program pencegahan yang dilaksanakan. Program-program tersebut dilihat menjurus kepada menyampaikan maklumat pendidikan pencegahan kepada pelajar sebagai langkah awal pencegahan daripada perbuatan salah laku. Dapatan ini menyokong pandangan Khadijah Rohani dan Nazariah (2007) yang menyatakan bahawa pendekatan pencegahan bertujuan 
untuk mendidik pelajar mengenal pasti kebaikan dan keburukan sekiranya mereka terlibat dalam sesuatu tingkah laku. Selain itu, analisis bagi min keseluruhan yang diperoleh daripada bahagian ini ialah 4.17 dan berada pada tahap skala setuju (3.50-4.49). Ini menunjukkan bahawa objektif pertama kajian ini iaitu untuk mengenal pasti pendekatan pencegahan oleh kaunselor Muslim dalam menangani salah laku pelajar memperoleh tahap persetujuan yang tinggi oleh responden:

Jadual 1: Pendekatan khas oleh kaunselor Muslim dalam menangani salah laku pelajar

\begin{tabular}{|c|c|c|c|c|c|c|}
\hline Pendekatan Program Khas & $\begin{array}{l}\text { Sangat } \\
\text { Tidak } \\
\text { Setuju }\end{array}$ & $\begin{array}{l}\text { Tidak } \\
\text { Setuju }\end{array}$ & $\begin{array}{l}\text { Tidak } \\
\text { Pasti }\end{array}$ & Setuju & $\begin{array}{l}\text { Sangat } \\
\text { Setuju }\end{array}$ & Min \\
\hline 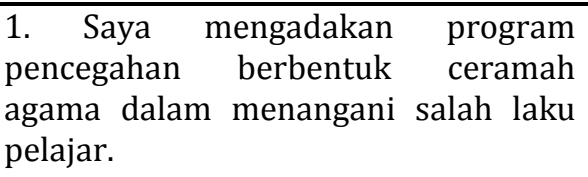 & $\begin{array}{l}0 \\
0.0 \%\end{array}$ & $\begin{array}{l}3 \\
4.1 \%\end{array}$ & $\begin{array}{l}5 \\
6.8 \%\end{array}$ & $\begin{array}{l}41 \\
56.2 \%\end{array}$ & $\begin{array}{l}24 \\
32.9 \%\end{array}$ & 4.18 \\
\hline $\begin{array}{l}\text { 2. Saya mengadakan program } \\
\text { pencegahan berbentuk ceramah anti } \\
\text { rokok, HIV dan AIDS dalam } \\
\text { menangani salah laku pelajar. }\end{array}$ & $\begin{array}{l}0 \\
0.0 \%\end{array}$ & $\begin{array}{l}0 \\
0.0 \%\end{array}$ & $\begin{array}{l}3 \\
4.1 \%\end{array}$ & $\begin{array}{l}41 \\
56.2 \%\end{array}$ & $\begin{array}{l}29 \\
39.7 \%\end{array}$ & 4.36 \\
\hline $\begin{array}{l}\text { 3. Saya mengadakan program } \\
\text { pencegahan berbentuk lawatan ke } \\
\text { pusat pemulihan akhlak dalam } \\
\text { menangani salah laku pelajar. }\end{array}$ & $\begin{array}{l}3 \\
4.1 \%\end{array}$ & $\begin{array}{l}12 \\
16.4 \%\end{array}$ & $\begin{array}{l}10 \\
13.7 \%\end{array}$ & $\begin{array}{l}36 \\
49.3 \%\end{array}$ & $\begin{array}{l}12 \\
16.4 \%\end{array}$ & 3.58 \\
\hline $\begin{array}{l}\text { 4. Saya mengadakan program } \\
\text { pencegahan berbentuk pameran anti } \\
\text { rokok, HIV dan AIDS dalam } \\
\text { menangani salah laku pelajar. }\end{array}$ & $\begin{array}{l}0 \\
0.0 \%\end{array}$ & $\begin{array}{l}1 \\
1.4 \%\end{array}$ & $\begin{array}{l}2 \\
2.7 \%\end{array}$ & $\begin{array}{l}43 \\
58.9 \%\end{array}$ & $\begin{array}{l}27 \\
37.0 \%\end{array}$ & 4.32 \\
\hline $\begin{array}{l}\text { 5. Saya mengadakan program } \\
\text { pencegahan berbentuk kursus jati diri } \\
\text { dalam menangani salah laku pelajar. }\end{array}$ & $\begin{array}{l}0 \\
0.0 \%\end{array}$ & $\begin{array}{l}1 \\
1.4 \%\end{array}$ & $\begin{array}{l}2 \\
2.7 \%\end{array}$ & $\begin{array}{l}44 \\
60.3 \%\end{array}$ & $\begin{array}{l}26 \\
35.6 \%\end{array}$ & 4.30 \\
\hline 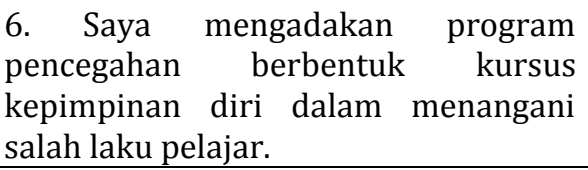 & $\begin{array}{l}0 \\
0.0 \%\end{array}$ & $\begin{array}{l}1 \\
1.4 \%\end{array}$ & $\begin{array}{l}3 \\
4.1 \%\end{array}$ & $\begin{array}{l}45 \\
61.6 \%\end{array}$ & $\begin{array}{l}24 \\
32.9 \%\end{array}$ & 4.26 \\
\hline
\end{tabular}

Di samping itu, kajian ini juga bertujuan untuk menganalisis amalan pendekatan Islam oleh kaunselor Muslim sekolah menengah di daerah Klang dalam menangani salah laku pelajar. Hasil kajian mendapati wujud amalan pendekatan Islam oleh kaunselor Muslim dalam menangani salah laku pelajar melalui pendekatan pencegahan yang dilaksanakan oleh mereka. Item yang mendapat nilai tertinggi dari segi analisis min ialah 'Saya sentiasa membimbing klien supaya tidak meninggalkan solat fardu lima waktu sehari semalam' (min=4.52) diikuti kedua tertinggi ialah item 'Saya sentiasa membimbing klien supaya tidak bersifat dengan sifat mazmumah (keji)' dan item 'Saya sentiasa membimbing klien supaya tidak mengabaikan hubungan baik sesama manusia dan alam sekitar' iaitu masing-masing mencapai nilai min=4.38. Selain itu, item 'Saya sentiasa membimbing klien supaya tidak melakukan perbuatan mungkar yang mendapat balasan dosa daripada Allah' (min=4.34). Manakala item yang mendapat nilai 
terendah 'Saya sentiasa membimbing klien supaya tidak terlalu terpengaruh dengan media massa serta perkembangan sains dan teknologi yang pesat' $(\min =4.21)$. Ini menunjukkan responden bersetuju dengan pendekatan pencegahan yang dilaksanakan iaitu membimbing pelajar mengenai aspek ibadat khusus dan aspek akhlak dalam menangani salah laku pelajar.

Dapatan kajian ini menunjukkan bahawa responden berusaha mengamalkan pendekatan Islam dalam menangani salah laku pelajar di sekolah. Ini berdasarkan kepada nilai min bagi setiap item adalah 4.0 dan ke atas yang menunjukkan tahap persetujuan yang tinggi. Berdasarkan analisis yang dilakukan responden bersetuju bahawa mereka sentiasa membimbing pelajar supaya sentiasa solat lima waktu sehari semalam. Persetujuan ini dapat dilihat pada dapatan item 'Saya sentiasa membimbing klien supaya tidak meninggalkan solat fardu lima waktu sehari semalam' mencatatkan peratusan yang tertinggi iaitu sebanyak 97.3\%. Ini membuktikan bahawa responden sentiasa prihatin terhadap amalan kerohanian pelajar iaitu solat lima waktu yang merupakan kewajipan ke atas setiap Muslim. Justeru, dapatan ini disokong dengan pernyataan Othman Najati (1992) yang menyatakan bahawa pencegahan jiwa manusia berasaskan solat fardu lima waktu merupakan kaedah pencegahan dan terapeutik yang mampu untuk mendidik keperibadian manusia. Malah, kewajipan menunaikan solat fardu ini secara jelas dapat mencegah perbuatan yang keji berdasarkan ayat al-Quran daripada surah al- 'Ankabut ayat 45.

Hasil kajian ini juga menunjukkan bahawa secara tidak langsung responden turut membimbing pelajar mengenai tingkah laku yang memperoleh pahala atau dosa, halal atau haram. Dapatan menunjukkan responden turut memberi maklumat mengenai pendidikan Islam seperti membimbing untuk meninggalkan sifat mazmumah, membimbing pelajar untuk menjaga hubungan baik sesama makhluk dan bimbingan kesan terpengaruh kepada perkaraperkara negatif seperti pengaruh negatif media massa dan perkembangan sains dan teknologi. Dapatan ini menyokong model perkhidmatan kaunseling Islam yang dikemukakan oleh Amaludin (2005) mengenai pendekatan pencegahan seperti menyuruh kepada kebaikan (makruf), mencegah daripada kejahatan (mungkar), memberi maklumat berkaitan akhlak dan salah laku, serta membimbing klien agar dapat membezakan di antara perbuatan yang mendapat dosa, pahala, perkara yang halal dan haram. Hasil kajian ini didapati turut disokong oleh pendapat (Aziz 1996) berkenaan dengan tujuan kaunseling iaitu membantu dan memberi kefahaman kepada klien dalam menghadapi cabaran persekitaran, membimbing klien yang terlibat dalam perbuatan keji seperti maksiat, penyalahgunaan dadah, disiplin di sekolah dan segala perkara yang dilarang oleh Allah (s.w.t.) selain membantu membentuk tabiat diri klien agar sentiasa berdisiplin:

Jadual 2: Kekerapan, peratusan dan min pendekatan pencegahan kaunselor Muslim dalam menangani salah laku pelajar.

\begin{tabular}{|c|c|c|c|c|c|c|}
\hline Pendekatan Pencegahan & $\begin{array}{l}\text { Sangat } \\
\text { Tidak } \\
\text { Setuju }\end{array}$ & $\begin{array}{l}\text { Tidak } \\
\text { Setuju }\end{array}$ & $\begin{array}{l}\text { Tidak } \\
\text { Pasti }\end{array}$ & Setuju & $\begin{array}{l}\text { Sangat } \\
\text { Setuju }\end{array}$ & Min \\
\hline $\begin{array}{l}\text { 1. Saya sentiasa membimbing klien } \\
\text { supaya tidak meninggalkan solat } \\
\text { fardhu lima waktu sehari semalam. }\end{array}$ & $\begin{array}{l}0 \\
0.0 \%\end{array}$ & $\begin{array}{l}0 \\
0.0 \%\end{array}$ & $\begin{array}{l}2 \\
2.7 \%\end{array}$ & $\begin{array}{l}31 \\
42.5 \%\end{array}$ & $\begin{array}{l}40 \\
54.8 \%\end{array}$ & 4.52 \\
\hline $\begin{array}{l}\text { 2. Saya sentiasa membimbing klien } \\
\text { supaya tidak bersifat dengan sifat } \\
\text { mazmumah (keji). }\end{array}$ & $\begin{array}{l}0 \\
0.0 \%\end{array}$ & $\begin{array}{l}0 \\
0.0 \%\end{array}$ & $\begin{array}{l}2 \\
2.7 \%\end{array}$ & $\begin{array}{l}41 \\
56.2 \%\end{array}$ & $\begin{array}{l}30 \\
41.1 \%\end{array}$ & 4.38 \\
\hline 3. Saya sentiasa membimbing klien & 0 & 0 & 4 & 37 & 32 & \\
\hline
\end{tabular}


Halimah Abd Halim \& Zainab Ismail

supaya tidak mengabaikan hubungan baik sesama manusia dan alam sekitar.

4. Saya sentiasa membimbing klien supaya tidak melakukan perbuatan munkar yang mendapat balasan dosa daripada Allah.

5. Saya sentiasa membimbing klien supaya tidak terlalu terpengaruh dengan media massa serta perkembangan sains dan teknologi yang pesat. $\begin{array}{llllll}0.0 \% & 0.0 \% & 5.5 \% & 50.7 \% & 43.8 \% & 4.38\end{array}$

$\begin{array}{lllll}0 & 0 & 4 & 40 & 29\end{array}$

$0.0 \% \quad 0.0 \% \quad 5.5 \% \quad 54.8 \% \quad 39.7 \%$

$\begin{array}{lllll}0 & 1 & 5 & 45 & 22\end{array}$

$0.0 \% \quad 1.4 \% \quad 6.8 \% \quad 61.6 \% \quad 30.1 \%$

9

$39.7 \%$

4.21

Ringkasnya, kajian ini menggambarkan bahawa pendekatan pencegahan yang dilaksanakan oleh kaunselor Muslim dalam menangani salah laku pelajar sekolah menengah di daerah Klang ini terdapatnya program berbentuk hubungan dengan Allah (s.w.t.) dan program berbentuk hubungan dengan manusia dan persekitaran. Menurut Ibn Kathir (2007, Jil. 1) manusia yang berpegang teguh dengan agama Allah (s.w.t.) dan menjaga hubungan dengan manusia sahaja akan dimuliakan serta memperoleh perdamaian sesama manusia. Oleh yang demikian, kajian ini menunjukkan bahawa kaunselor Muslim di sekolah menengah daerah Klang sentiasa menitikberatkan pendekatan pencegahan berbentuk hubungan dengan Allah (s.w.t.), hubungan dengan manusia dan persekitaran dalam usaha untuk menangani salah laku pelajar demi memperoleh kemuliaan dan keredaan-Nya.

Kajian ini mendapati kaunselor Muslim sekolah menengah di daerah Klang, Selangor mempunyai tahap persetujuan yang positif terhadap program pencegahan yang dianjurkan merangkumi program berbentuk ceramah, pameran, kursus dan lawatan dalam usaha mereka menangani salah laku pelajar. Selain itu, kajian juga mendapati kaunselor Muslim bersetuju dengan pendekatan pencegahan yang diamalkan iaitu berbentuk bimbingan terhadap ibadat khusus iaitu solat lima waktu dan bimbingan terhadap aspek akhlak dalam menangani salah laku pelajar. Kesemua aspek ini memperlihatkan pendekatan Islam yang diamalkan oleh kaunselor Muslim. Kajian ini didapati tidak bertentangan dengan kajian oleh Zulkifle (2007), Khalim dan Wan Zulkifli (2009) yang dilihat selari dalam empat aspek pendekatan pencegahan iaitu program pencegahan salah laku, memberi maklumat, bimbingan dan kaunseling. Implikasi daripada kajian ini dapat membina indikator pendekatan pencegahan dalam kaunseling bagi menangani salah laku pelajar. Justeru, kajian ini mencadangkan kaunselor Muslim supaya mempergiatkan usaha dalam menangani salah laku pelajar secara afektif melalui program pencegahan yang bersifat holistik dan seimbang meliputi aspek intelek, jasmani, emosi, dan rohani agar dapat melahirkan pelajar yang berdisiplin, beriman dan beramal soleh. Selain itu, pendekatan pencegahan oleh kaunselor Muslim dalam menangani salah laku pelajar ini wajar disepadukan dengan pendekatan pemulihan malah pendekatan perkembangan yang merupakan aspek penting untuk pembangunan potensi diri pelajar khususnya dan secara langsung mampu mengurangkan kes salah laku serta dapat mewujudkan persekitaran sekolah yang selamat. 


\section{References}

Al-Quran.

Abd Kadir Talib. 1990. Konsep manusia dan ciri-ciri khusus kaunselor/perundingcara dalam kaunseling menurut perspektif Islam. Kertas Kerja Seminar Kebangsaan Kaunseling dalam Masyarakat Islam. Kuala Lumpur, 25-26 September.

Abu Mansor Mat Urdi bin Yahaya. 2005. Pengaruh amalan agama terhadap disiplin di kalangan pelajar Muslim sekolah menengah. Tesis Sarjana, Fakulti Pendidikan, Universiti Malaya.

Amaludin Ab. Rahman. 2005. Keperluan perlaksanaan kaunseling Islam dalam menangani masalah sosial di kalangan remaja: satu kajian kes di pusat pemulihan akhlak di Malaysia. Tesis Ph.D, Fakulti Pengajian Islam, Universiti Kebangsaan Malaysia.

Aziz Salleh. 1996. Kaunseling Islam Asas. Kuala Lumpur: Utusan Publications \& Distributors Sdn. Bhd.

Hasan Langgulung. 1983. Psikologi dan Kesihatan Mental di Sekolah-sekolah. Bangi: Penerbit Universiti Kebangsaan Malaysia.

Ibn Kathir, Abi al-Fida' Isma il Ibn Kathir al-Qurshi al-Damshiqi. 1428H/2007. Tafsir al-Quran al-`Azim. Al-Majallat al-Awwal. Cairo: Dar al-Ghad al-Jadid.

Ishak Yussof \& Khairun Nisa Abd Razi. 2010. Menangani disiplin pelajar melalui pendekatan modal insan. Dlm. Zainab Ismail, Salasiah Hanin Hamjah \& Rosmawati Mohamad Rasit (pnyt.). Isu Dakwah Masa Kini Keluarga, Komuniti Marginal dan Pendidikan, hlm. 235251. Bangi: Jabatan Pengajian Dakwah dan Kepimpinan, Fakulti Pengajian Islam, Universiti Kebangsaan Malaysia.

Ishak Ismail. 2012. Budaya nilai-nilai keagamaan dan disiplin pelajar di sekolah menengah agama negeri Selangor Darul Ehsan. Tesis Ph.D., Fakulti Pendidikan, Universiti Kebangsaan Malaysia.

Ishammudin Ismail. 2000. Panduan Asas Kaunselor Muslim. Kajang: Aras Mega (M) Sdn. Bhd.

Jabatan Pendidikan Selangor. 2014. Sektor Pembangunan Kemanusiaan, Unit Hal Ehwal Murid, Statistik dan Laporan Peratusan Salah Laku Disiplin Murid Sekolah Menengah 2013. 15 September.

Kamal Abd Manaf. 1995. Kaunseling Islam Perbandingan antara Amalan dan Teori Kaunseling Barat. Kuala Lumpur: Utusan Publications \& Distributors.

Kementerian Pendidikan Malaysia. 1993. Panduan Perlaksanaan Perkhidmatan Bimbingan dan Kaunseling di Sekolah Menengah: Unit Bimbingan dan Kaunseling. t.tp.: t.pt.

Khadijah Rohani Mohd Yunus \& Nazariah Ab. Samad. 2007. Bimbingan dan Penasihatan Falsafah, Kemahiran, Proses dan Etika. Tanjung Malim: Universiti Pendidikan Sultan Idris.

Khalim Zainal \& Wan Zulkifli Wan Hassan. 2009. Pendekatan Islam dalam menangani masalah disiplin tegar dalam kalangan pelajar sekolah: satu kajian kes. Jurnal of Islamic and Arabic Education 1(2): 1-14.

Malek Muhamat Said. 2007. Mengurus Khidmat Bimbingan dan Kaunseling di Sekolah. Kuala Lumpur: PTS Professional Publishing Sdn. Bhd.

al-Maraghi, Ahmad Mustafa al-Maraghi. 1419H/1998. Tafsir al-Maraghi. Beirut: Dar al-Kutub al'Ilmiyyah.

Mardzelah Makhsin. 2012. Hisbah dan penghayatan akhlak murid-murid sekolah menengah. Tesis Ph.D, Fakulti Pendidikan, Universiti Kebangsaan Malaysia.

Maznah Baba \& Zainal Madon. 2007. Kaunseling Individu. Kuala Lumpur: PTS Professional Publishing Sdn. Bhd.

Mohamad Othman Najati. 1992. Psikoterapi Menurut al-Quran. Transl. Abd Rahman Ahmad. Kuala Lumpur: Human Resource Enterprise. 
Mohamed Sharif Mustaffa. 1998. Kaunseling Islam. Jurnal Pendidikan Universiti Teknologi Malaysia: $19-30$.

Mohamed Sharif Mustaffa, Roslee Ahmad \& Sulaiman Shakib Mohd Noor. 2003. Ciri-ciri kaunselor dan pendekatan Kaunseling Islam. Kertas Kerja Seminar Antarabangsa GuruGuru Agama Singapura. Singapura.

Najati, Muhammad Uthman. 2001. Al-Quran wa al-'Ilm al-Nafs. Cairo: Dar al-Shuruq.

Sapora Sipon. 2002. Gejala sosial di kalangan pelajar dan keperluan perkhidmatan bimbingan dan kaunseling. Kertas Kerja Seminar Hala Tuju Kaunseling di Malaysia. Kuala Lumpur.

Siti Hairaney Bachok. 2004. Amalan kaunseling pendekatan Islam di kalangan kaunselor: satu kajian kes di daerah Johor Bahru. Tesis Sarjana, Fakulti Pendidikan, Universiti Teknologi Malaysia.

Zulkefli Ismail. 2007. Pendekatan pentadbir sekolah dalam menangani salah laku murid sekolah menengah di Kuala Lumpur. Tesis Sarjana, Fakulti Pendidikan, Universiti Malaya. 